\title{
Pigeons fail to detect low-frequency magnetic fields
}

\author{
BRUCE R. MOORE, KELLY J. STANHOPE, and DAVID WILCOX \\ Dalhousie University, Halifax, Nova Scotia, Canada
}

\begin{abstract}
In an attempt to resolve basic inconsistencies in the literature on magnetic reception in birds, we tested 4 pigeons for possible sensitivity to low-frequency magnetic fields. Horizontal and vertical components of an earth-strength field were varied at frequencies of 0.01 to $10 \mathrm{~Hz}$. None of the pigeons seemed able to distinguish between varying and static fields, although each received 1,800 trials of discrimination training. These results, related findings, and the reported failure to replicate a critical field study lead the authors to question the prevailing belief that pigeons can detect magnetic fields.
\end{abstract}

Until 1971 most relevant studies indicated that birds were unable to detect magnetic fields (see Keeton, 1971). The more recent literature, however, has been mixed. Studies employing conditioning (psychophysical) techniques have continued to give primarily negative results (Alsop, 1987; Beaugrand, 1976, 1977; Carman, Walker, \& Lee, 1987; Delius \& Emmerton, 1978; Griffin, 1982; Kreithen \& Keeton, 1974; McIsaac \& Kreithen, 1987; see also Meyer \& Lambe, 1966; Neville, 1955; Orgel \& Smith, 1954; cf. Bookman, 1977; Reille, 1968). But other sorts of studies have led to many reports of magnetic effects upon birds (e.g., Keeton, 1971; Keeton, Larkin, \& Windsor, 1974; Walcott \& Green, 1974; Wiltschko \& Wiltschko, 1972). There are several possible interpretations of this inconsistency.

One possibility is that birds may be sensitive to some fields but not to others; for example, they may be sensitive only to fields that change, or to those that change within some limited range of frequencies.

Both Keeton (1974) and Emlen (1975) suggested that navigating birds may use geomagnetic landmarks to help determine their positions. In flying over crustal anomalies of various spatial wavelengths, a bird would obviously be exposed to slowly changing fields. It occurred to us several years ago that the wavelengths to which such birds could be exposed would be limited in two ways. First, flight altitude would limit exposure to short spatial wavelengths, and would therefore act as a low-pass temporal frequency filter. Additionally, for homing pigeons that had just been released, the diameter of the typical circling pattern would limit exposure to long spatial wavelengths; this would act as a high-pass temporal fre-

Supported by the Natural Sciences and Engineering Research Council of Canada. We thank B. F. Moore, D. R. Griffin, H. James, and M. L. Spetch for helpful criticism of the manuscript. D. Wilcox is now in the Medical School of Dalhousie University and $\mathrm{K}$. Stanhope is in the Department of Experimental Psychology at the University of Cambridge. Address correspondence to Bruce R. Moore, Department of Psychology, Dalhousie University, Halifax, Nova Scotia B3H 4J1, Canada. quency filter. To a first approximation, these two factors might permit exposure to waves with periods between 0.10 and $100 \mathrm{sec}$-that is, to frequencies between 0.01 and $10 \mathrm{~Hz}$.

Five published conditioning studies have involved frequencies in this range. Reille (1968) reported that pigeons were able to detect $0.2-0.5-\mathrm{Hz}$ fields. A better controlled study by Kreithen and Keeton (1974) failed to replicate this finding; in that study, however, only the horizontal field component was varied, and sensitivity to vertical fields was not tested. Delius and Emmerton (1978) also reported no detection of 0.5 - and $10-\mathrm{Hz}$ horizontal fields. Bookman (1977) reported positive findings from a procedure in which birds moved slowly beneath vertical magnetic coils. His birds were thus exposed to slowly changing vertical fields in a situation analogous to the overflight of crustal anomalies. This finding, however, has also proved difficult to replicate (Carman et al., 1987; see also McIsaac \& Kreithen, 1987).

Positive effects have also been claimed in several field studies in which low-frequency magnetic fields were undoubtedly present (Keeton, 1971; Keeton et al., 1974; Walcott \& Green, 1974). Both the bar magnets worn by pigeons in Keeton's (1971) study and the magnetic coils worn by the birds of Walcott and Green (1974) necessarily moved with each flexure of the animals' bodies during ordinary flight. The resulting fields near the animals' heads therefore varied at frequencies well below $10 \mathrm{~Hz}$.

Finally, magnetic storms were reported by Keeton et al. (1974) to affect the orientation of homing pigeons. Such storms contain magnetic waves in the $0.005-2.0 \mathrm{~Hz}$ range (Campbell, 1967).

Although not all of these studies are entirely persuasive (see also Discussion), they collectively led us to examine the species' sensitivity to low-frequency magnetic fields. In the present experiment, the birds were given extensive training (1,800 trials) to allow ample time for learning. In the absence of learning, extended training would minimize sampling errors, causing the subjects to cluster more tightly at chance level. 


\section{METHOD}

Subjects

Four adult male White Carneaux pigeons were tested. The birds had free access to food throughout the study, but their water intake was limited to 13-15 ml per day.

\section{Apparatus}

The birds were tested in a single-key conditioning chamber constructed of nonmagnetic materials. One end of the chamber was formed by an aluminum panel $28 \mathrm{~cm}$ wide and $36 \mathrm{~cm}$ high. A water delivery spout, a small signal light, a standard (Lehigh Valley) response key, and a houselight were centered on this wall at heights of 15, 17.5, 25.5, and $34 \mathrm{~cm}$, respectively. The 38-cm-long floor was also aluminum. The rest of the chamber was made of plywood and clear Plexiglas.

The chamber was positioned near the center of a system of two 1.2-m-diam pairs of Helmholtz coils. Electric currents within the coils were produced and controlled by a Hewlett-Packard 3310B function generator, dc power amplifier, and appropriate rheostats. The magnetic fields generated by these currents were locally uniform within the conditioning chamber. One Helmholtz pair controlled the vertical component of the field; the other was aligned axially with magnetic north and controlled the horizontal component. The fields were varied sinusoidally at frequencies of 10,1 , 0.1 , or $0.01 \mathrm{~Hz}$. The system was adjusted so that the peak current flow in one direction doubled, and in the other direction canceled, both components of the natural $\left(0.480 \mathrm{G} / 48,000 \mathrm{nT}, 72^{\circ}\right)$ geomagnetic field within the chamber. Calibration was done with a Schoenstadt DM-2220 fluxgate magnetometer, and was accurate within $2 \%$.

\section{Procedure}

Each bird was trained to contact the response key for a $0.2-\mathrm{ml}$ water reward. We therefore conditioned a drinking-like reaction, as described by Jenkins and Moore (1973). When responding was well established, reinforcement was made intermittent; it was ultimately delivered once per minute, on average, on a (geometric) variable-interval schedule (Millenson, 1963). Throughout this period the magnetic field within the chamber was varied sinusoidally. One bird was trained at each of the specified frequencies $(10,1,0.1$, and $0.01 \mathrm{~Hz}$ ).

Each bird was then tested on a simple discrimination in which the field sometimes varied at the usual (training) frequency and sometimes reverted to the natural (static) level. Rewards were available on the accustomed schedule in the alternating field, but were not available when the field was static. Each positive field continued until reinforcement was given. The negative trials were matched in all respects, except that the fields were static and ended with unreinforced responses. The positive and negative fields were intermixed in random order. Each session ended when 30 rewards had been given. Each pigeon was tested once daily for 30 days.

\section{RESULTS}

If they were able to discriminate between constant and changing fields, the birds should have continued to respond in the latter but ceased to respond in the former. As a measure of discrimination between the two conditions, a traditional discrimination ratio was used: each bird's mean response rate in the positive condition was divided by the sum of its positive and negative rates. Thus, perfect discrimination between fields would give a ratio of 1.0, whereas absolute failure to discriminate would give a ratio of 0.5 .
Table 1

Response Rates and Discrimination Ratios

\begin{tabular}{cccc}
\multicolumn{4}{c}{ Response Rates and Discrimination Ratios } \\
\cline { 2 - 4 } Bird & \multicolumn{2}{c}{ Responses per Minute } & \\
\cline { 2 - 4 } & Positive & Negative & Ratios \\
\hline 1 & 10.37 & 10.04 & 0.508 \\
2 & 21.81 & 20.94 & 0.510 \\
3 & 41.64 & 43.72 & 0.488 \\
4 & 14.26 & 14.63 & 0.494 \\
Mean & 22.02 & 22.33 & 0.500 \\
\hline
\end{tabular}

In spite of extensive training, no bird appeared to distinguish between the constant and changing fields. The outcome (Table 1) was unambiguously negative. The mean discrimination ratio was 0.500 , with a standard error of less than $1 \%$.

\section{DISCUSSION}

Our data do not explain the inconsistency of the literature. Rather, they agree with the great majority of psychophysical studies and with an important experiment published after completion of our work, which found no effect of slowly changing $(0.003 \mathrm{~Hz})$ fields upon the pigeons' homing behavior (Lednor \& Walcott, 1983).

What, then, are we to make of the literature's inconsistency? Several writers have suggested, some more strongly than others, that the negative psychophysical literature may simply reflect biological constraints upon learning (Beaugrand, 1976, 1977; Carman et al., 1987; Emlen, 1975; Orgel \& Smith, 1954; Ossenkopp \& Barbeito; 1978). That is, it has been suggested that birds may be capable of detecting magnetic fields, yet fail to reveal this in unnatural conditioning tasks.

We do not believe that the negative psychophysical literature can reasonably be dismissed in this manner. It now includes absolute failures to demonstrate magnetic sensitivity in studies involving four sorts of reinforcers (food, water, shock, and shock avoidance) and five responses (heart rate, pecking, drinking movements, walking, and flying) (Alsop, 1987; Beaugrand, 1976, 1977; Carman et al., 1987; Delius \& Emmerton, 1978; Griffin, 1982; Kreithen \& Keeton, 1974; McIsaac \& Kreithen, 1987; Meyer \& Lambe, 1966; Orgel \& Smith, 1954). A great many other negative studies have remained unpublished (see Alsop, 1987; Bookman, 1977; Delius \& Emmerton, 1978; McIsaac \& Kreithen, 1987; Neville, 1955). Although there is no doubt that pigeons find it difficult to form certain unnatural associations (Moore, 1973), we know of no case in which a proven exteroceptive sensitivity has remained impossible to demonstrate clearly with conditioning techniques. Indeed, the remarkable consistency of the psychophysical findings suggests that we should look closely at any field study reporting positive effects.

The most influential of the positive studies was undoubtedly that of Keeton (1971), who reported that on overcast days, when the sun could not be used for direction, 
attaching small magnets to the backs of homing pigeons caused them to become disoriented. Unfortunately, Keeton himself was unable to replicate this finding, in spite of almost a decade of subsequent research involving 457 additional birds. The orientation of those with bar magnets did not differ significantly from that of control birds in tests conducted on overcast days. The mean vector lengths were 0.48 for birds with magnets, and 0.46 for controls. Five other standard measures of orientation and performance were also unaffected by magnets.

Keeton's (1971) study was critical, not only because it launched the modern literature on magnetic effects in vertebrates; it seemed also to provide the most solid of published findings in a literature plagued by procedural, statistical, and interpretive problems, and problems of replication. Without it, the positive literature is appreciably less persuasive; its status, we believe, is far from clear (Griffin, 1982).

\section{REFERENCES}

Alsop, B. (1987). A failure to obtain magnetic discrimination in the pigeon. Animal Learning \& Behavior, 15, 110-114.

Beaugrand, J. P. (1976). An attempt to confirm magnetic sensitivity in the pigeon, Columba livia. Journal of Comparative Physiology A, $110,343-355$.

Beaugrand, J. P. (1977). Test of magnetic sensitivity in seven species of European birds using a cardiac nociceptive conditioning procedure. Behavioural Processes, 2, 113-127.

Bookman, M. A. (1977). Sensitivity of the homing pigeon to an Earthstrength magnetic field. Nature, 267, 340-342.

Camprell, W. H. (1967). Geomagnetic pulsations. In S. Matsushita \& W. H. Campbell (Eds.), Physics of geomagnetic phenomena. New York: Academic Press.

Carman, G. J., Walker, M. M., \& Lee, A. K. (1987). Attempts to demonstrate magnetic discriminations by homing pigeons in flight. Animal Learning \& Behavior, 15, 124-129.

Delius, J. D., \& Emmerton, J. (1978). Sensory mechanisms related to homing in pigeons. In K. Schmidt-Koenig \& W. T. Keeton (Eds.), Animal migration, navigation, and homing (pp. 35-41). Berlin: Springer-Verlag.

EMLEN, S. T. (1975). Migration: Orientation and navigation. In D. S. Farner, J. R. King, \& K. C. Parkes (Eds.), Avian biology (Vol. 5, pp. 129-219). London: Academic Press.
GRIFFIN, D. R. (1982). Ecology of migration: Is magnetic orientation a reality? Quarterly Review of Biology, 57, 293-295.

Jenkins, H. M., \& MoORE, B. R. (1973). The form of the auto-shaped response with food or water reinforcers. Joumal of the Experimental Analysis of Behavior, 20, 163-181.

KeEton, W. T. (1971). Magnets interfere with pigeon homing. Proceedings of the National Academy of Sciences, 68, 102-106.

KeETON, W. T. (1974). The orientational and navigational basis of homing in birds. Advances in the Study of Behaviour, 5, 47-132.

KeEToN, W. T., LARKIN, T. S., \& WINDSOR, D. W. (1974). Normal fluctuations in the earth's magnetic field influence pigeon orientation. Journal of Comparative Physiology A, 95, 95-103.

KREITHEN, M. L., \& KEETON, W. T. (1974). Attempts to condition homing pigeons to magnetic stimuli. Journal of Comparative Physiology A, 91, 355-362.

LEDNOR, A. J., \& WALCOTT, C. (1983). Homing pigeon navigation: The effects of in-flight exposure to a varying magnetic field. Comparative Physiology \& Biochemistry, 76A, 665-671.

MclsAAC, H. P., KREITHEN, M. L. (1987). Attempts to condition homing pigeons to magnetic cues in an outdoor flight cage. Animal Learning \& Behavior, 15, 118-123.

Meyer, M. E., LAmbe, D. R. (1966). Sensitivity of the pigeon to changes in the magnetic field. Psychonomic Science, 5, 349-350.

MiLLENSON, J. R. (1963). Random interval schedules of reinforcement. Journal of the Experimental Analysis of Behavior, 2, 437-443.

MoORE, B. R. (1973). The role of directed Pavlovian reactions in simple instrumental learning in the pigeon. In R. A. Hinde \& J. S. Hinde (Eds.), Constraints on learning (pp. 159-186). London: Academic Press.

NeVILLE, J. R. (1955). An experimental study of magnetic factors possibly concerned with bird navigation. Unpublished doctoral dissertation, Stanford University.

ORGEL, A. R., SMITH, J. C. (1954). Test of the magnetic theory of homing. Science, 120, 891-892.

OSSENKOPP, K.-P., BARBEITO, R. (1978). Bird orientation and the geomagnetic field: A review. Neuroscience \& Biobehavioral Reviews, 2, 255-270.

ReILle, A. (1968). Essai de mise en évidence d'une sensibilité du pigeon au champ magnétique à l'aide d'un conditionnement nociceptif. Joumal de Physiologie (Paris), 60, 85-92.

WalcotT, C., \& GreEN, R. P. (1974). Orientation of homing pigeons altered by a change in the direction of an applied magnetic field. Science, 184, 180-182.

Wiltschko, W., \& Wiltschko, R. (1972). Magnetic compass of European robins. Science, 176, 62-64.

(Manuscript received November 5, 1985; revision accepted for publication July 23,1986 .) 